\title{
Herd- and Cow-Level Prevalence of Digital Dermatitis in The Netherlands and Associated Risk Factors
}

\author{
M. Holzhauer, ${ }^{\star 1}$ C. Hardenberg,† C. J. M. Bartels, ${ }^{\star}$ and K. Frankena† \\ ${ }^{*}$ GD Ltd., 7400 AA Deventer, The Netherlands \\ †Quantitative Veterinary Epidemiology Group, Wageningen Institute of Animal Sciences Wageningen, \\ $6700 \mathrm{AH}$ Wageningen, The Netherlands
}

\section{ABSTRACT}

The objective of this cross-sectional study was to reevaluate the prevalence of digital dermatitis (DD) and associated risk factors in The Netherlands. Between May 2002 and December 2003, information about the presence or absence of DD lesions and other claw disorders on the hind claws of dairy cows in The Netherlands was collected by 20 hoof trimmers during trimming of all dairy cows in 383 herds. A questionnaire was used to acquire information regarding management and housing. Additional information, such as parity, breed, and stage of lactation of the cows, was provided by the Dutch Herd Book Organization. Digital dermatitis was present in $21.2 \%(\mathrm{SE}=0.3)$ of the study population $(\mathrm{n}=$ 22,454 cows). The herd prevalence varied from $0 \%(9.1 \%$ of the herds) to $83.0 \%$. Most common was herd prevalence between 5 and $10 \%$. The Holstein-Friesian breed was at higher risk for DD [odds ratio $(\mathrm{OR})=1.7$ ] than was the Meuse Rhine IJssel breed (dual purpose breed). The risk for DD decreased with increasing parity. Cows at the peak of their lactation (30 to $60 \mathrm{~d}$ in milk) and in the third parity had higher odds for DD in comparison with cows that were later than 60 DIM. The presence of other claw disorders, such as interdigital dermatitis/ heel horn erosion (IDHE), interdigital hyperplasia (HYP), and interdigital phlegmon, appeared to be predisposing for DD. Based on estimation of the population-attributable fraction, it was concluded that if IDHE, HYP, and interdigital phlegmon were not present among the study population, respectively, 32.2, 9.0, and $1.1 \%$ of the DD cases could have been prevented. The risk for DD slightly decreased when cows affected by IDHE had access to pasture. Because of the interrelation between infectious claw disorders, an effective intervention strategy against DD should focus on an integrated approach to the control of all infectious claw diseases. Cows trimmed $>12$ mo before the study (during regular trimming of the entire herd) were at lower

Received July 7, 2005.

Accepted October 4, 2005.

${ }^{1}$ Corresponding author: m.holzhauer@gdvdieren.nl risk for DD than were cows that were trimmed at shorter intervals. Animals that had $>8 \mathrm{~h}$ of access to pasture were at higher risk for $\mathrm{DD}(\mathrm{OR}=1.6)$ compared with no access to pasture. Finally, cows in small-sized herds $(<45$ cows) affected with HYP were at lower risk $(\mathrm{OR}=0.6)$ for DD than were cows affected with HYP in medium- and large-sized herds (60 to 85 cows per herd). Key words: digital dermatitis, risk factor, claw disorder, epidemiology

\section{INTRODUCTION}

Digital dermatitis (DD), a digital skin disease of cattle, was first described in 1974 in Italy and is characterized by inflammation of the skin, most times in the region of the bulb of the heel and coronet of the claw (Cheli and Mortellaro, 1974). Today, the disease has spread all over the world and has been reported at an endemic stage in the United Kingdom, The Netherlands, and most other countries in western and southern Europe and the United States. (Brizzi, 1993; van Amstel et al., 1995; Clarkson et al., 1996; RodriguesLainz et al., 1996, 1999; Read and Walker, 1998a; Wells et al., 1999; Murray et al., 2002; Somers et al., 2003). In other countries, such as Japan, Australia, and New Zealand, DD is treated as an incidental lesion (Kimura et al., 1993; McLennan and McKenzie, 1996; Vermunt and Hill, 2004). However, in Norway, DD is being considered increasingly problematic because of the switching from current tie-stall housing systems to free stalls (Sogstad et al., 2005). This is in accordance with the results of a recent Dutch study, where a clear influence of housing system on DD prevalence was found (Somers et al., 2003).

The most important clinical symptoms of DD are lameness, lifting of the foot, and walking on the tip of the toe (Blowey and Sharp, 1988; Basset et al., 1990; Read and Walker, 1998a). A localized circumscribed dermatitis is present, which is painful at palpation (Blowey and Sharp, 1988). The animals are not systemically ill (Cornelisse et al., 1981; Dawson, 1999). Affected cows often have decreased milk production (Nutter and Moffit, 1990; van Amstel et al., 1995; Argaez-Rodriguez, et 
al., 1997) and deteriorated reproductive performance (Argaez-Rodriguez et al., 1997; Socha et al., 2002; Garbarino et al., 2004). Although it is known that lameness is currently the third most expensive disorder following mastitis and fertility disorders, the costs specifically associated with DD are not identified (Enting et al., 1997).

Digital dermatitis was first noticed in The Netherlands in 1980 as a sporadically occurring new claw lesion (Cornelisse et al., 1981). In later studies, DD was reported at a more endemic stage, whereby cow level prevalences were estimated at 11, 18, and 30\% (Frankena et al., 1991; Smits et al., 1992; Somers et al., 2003).

In The Netherlands today, DD is commonly referred to as Mortellaro disease, but internationally it has several other names such as papillomatous DD (Read and Walker, 1998b; Rodrigues-Lainz, 1999; Wells et al., 1999), foot warts (Read and Walker, 1998b), strawberry foot rot, Italian foot rot, raspberry heel, hairy warts, hairy heel warts, hairy foot warts, or heel warts (Demirkan et al., 2000). Throughout this paper, the term DD will be used.

The main risk factors associated with DD found in Dutch and American studies were breed, stage of lactation, parity, herd size, housing system, purchase of heifers, trimming and footbath regimen, nutrition, and season. In the Dutch study of Frankena et al. (1991), the Holstein-Friesian breed was considered a risk factor in comparison with the Dutch Meuse Rhine IJssel breed (MRIJ). Both Dutch and American studies showed that first-parity cows were at higher risk for DD than were older cows (Frankena et al., 1991; Smits et al., 1992; Read and Walker, 1998a; Somers et al., 2005a). In these same studies, it appeared that lactating cows were at higher risk for DD than were dry cows. In the study of Frankena et al. (1991) it was also observed that cows at the top of production were at high risk for DD. In The Netherlands, a medium herd size (50 to 65 cows) appeared to be a risk factor for DD (Frankena et al., 1991). However, in the United States, large herds (>200 cows) appeared to be predisposed (Wells et al., 1999). In respect to housing, studies in The Netherlands and in the United States showed a rough floor as a risk factor for DD (Frankena et al., 1991; Wells et al., 1999; Somers et al., 2005a). Frankena et al. (1991) found a large distance between rail and wall in the cubicles as a predisposing factor. Both Frankena et al. (1991) and Somers et al. (2005a) found limited access to pasture as a risk factor. In the US study (Wells et al., 1999), it was concluded that the purchase of heifers was a risk factor for DD. In this same study, it appeared that cows trimmed by hoof trimmers who also operated on other farms were at higher risk. The effect of nutrition on DD has not been intensively studied. The Dutch study of Somers et al. (2005a) showed that a fast rise in concentrate uptake after calving was a risk factor for DD. Seasonal risk was observed in California, where the late spring and summer were risk periods.

The precise etiology of DD is not completely understood (Basset et al., 1990; Schroeder et al., 2003). Although several bacteria species are found in bacteriological examinations, the presence of the anaerobe spirochetes (specifically Treponema spp.) in the lesions is consistently found (Cornelisse et al., 1981; Blowey and Sharp, 1988; Döpfer et al., 1997; Read and Walker, 1998a,b; Demirkan et al., 1999; Murray et al., 2002; Trott et al., 2003). The disease is considered to be multifactorial, and cow factors, management factors, and environmental factors play a role in its clinical occurrence (Frankena et al., 1991; Rodrigues-Lainz et al., 1996, 1999; Argaez-Rodriguez et al., 1997; Somers et al., 2005a).

The most effective treatment for DD is topical application of oxytetracycline or gentian violet aerosol spray (Cornelisse et al., 1981; Blowey and Sharp, 1988; Manske et al., 2002b). Footbaths with copper solution or formalin are also used for prevention and control. However, reports about the effectiveness of this measure are not consistent (Nutter and Moffit, 1990; Manske et al., 2002b). Improper footbath management could also facilitate the spread of DD (Zemljic, 2004). Specifically, infrequent refreshing of footbaths may give the causative organisms the opportunity to build up, thus facilitating spread between cows (van Amstel et al., 1995).

The objective of this cross-sectional study was to determine the herd- and the cow-level prevalence of DD in The Netherlands and to reidentify and quantify possible interrelated risk factors. This study is part of an overall aim to improve claw health of dairy cattle in The Netherlands based on prevention and good herd health management.

\section{MATERIALS AND METHODS}

\section{Study Design and Population}

Between May 2002 and December 2003, 28 professional hoof trimmers collected information about the presence or absence of DD on the hind claws of 25,829 cows on 431 dairy farms as part of a project of the Dutch Animal Health Service Ltd. Information such as identification and registration number of the cows and date of trimming was recorded. A questionnaire, completed by the farmer and hoof trimmer, was used to acquire information regarding management and housing. Information about breed, parity, and previous calving date was obtained from the Dutch herd book organization, NRS. 
Hoof trimmers were requested to randomly select herds in which trimming of the whole herd occurred on a routine basis. Data collection was done with the consent of the farmer, and the farms could participate only once in the study. The herds were mainly located in the eastern and northern part of The Netherlands. About $90 \%$ of the study population consisted of purebred and crossbred Holstein-Friesian dairy cattle. Approximately $90 \%$ of the cows were housed in free stalls with a slatted floor.

Scoring for DD in this study was performed based on visual inspection, smell, and pain reactions of the cows based on the international standardized diagnosis as described by Espinasse et al. (1982); lesions were noted as absent or present on the hind claws. The hoof trimmers were trained by an expert of the Animal Health Service prior to recording to assure uniformity in scoring. In addition to $\mathrm{DD}$, the presence of other lesions such as interdigital dermatitis/heel horn erosion (IDHE), sole hemorrhages, chronic laminitis, White Line Disease, sole ulcer, interdigital hyperplasia (HYP), and interdigital phlegmon (IP) was recorded.

\section{Statistical Analysis}

Individual cows for which information was missing were excluded from the analysis. Finally, 22,454 cows from 383 farms trimmed by 20 hoof trimmers remained for the risk factor analysis for DD.

The model building procedure consisted of several steps. The data were checked for missing values and typing errors using descriptive statistics (e.g., PROC MEANS, PROC FREQ, and PROC UNIVARIATE) in SAS 9.1 (SAS Institute, 2004). After this validation, a univariable analysis was conducted using the LOGISTIC procedure in SAS (2004). Table 1 shows all of the variables that were initially analyzed.

All variables that were associated with DD in the univariable analysis (deviance difference, $P<0.25$ ) were included in the multivariable model. Next, a backwards procedure was performed in which the variable showing the highest $P$-value was deleted. A $P$-value of $\leq 0.05$ was considered to be a significant association. The model was refitted, and the deviance difference was calculated to check whether deletion of the variable affected the model significantly. Second, in case a variable was removed from the model and the estimates of the other variables in the model changed $>25 \%$ (or $>0.1$ if $-0.4<\beta<0.4$ ), the removed variable was considered to be a confounder and was thus retained in the model (Frankena and Graat, 2001).

Biologically logical interaction terms were added to the model and were tested by looking at the significance of the deviance difference when excluding the interac-
Table 1. Overview of the variables tested in the univariable analysis for association with digital dermatitis in 22,454 Dutch dairy cows (383 herds)

\begin{tabular}{ll}
\hline Variable \\
\hline Parity \\
Stage of lactation \\
Breed \\
Presence of interdigital dermatitis/heel horn erosion \\
Presence of sole hemorrhage \\
Presence of chronic laminits \\
Presence of White Line Disease \\
Presence of sole ulcer \\
Presence of interdigital hyperplasia \\
Presence of interdigital phlegmon \\
Floor type \\
Manure scraper \\
Access to pasture \\
Walking path to pasture \\
Bedding \\
Purchase of heifers \\
Herd size \\
Use of footbath \\
Content of footbath \\
Size of footbath \\
Hoof trimming interval \\
Season of hoof trimming
\end{tabular}

tion from the model. This backwards procedure was repeated until only significant interactions remained in the model. No 3-way interactions were tested.

The observations were not necessarily independent, and a cluster effect of herd and hoof trimmer was possibly present. To test whether this hierarchical data structure was present, multilevel analysis using MLWIN 2.01 (2004) was performed. The binomial response model used a default quasi-likelihood procedure for estimation. To have the most accurate estimates, second-order Taylor expansion and PQL (penalized, predictive, quasi-likelihood) were used (MLWIN User's Guide, 2004).

Subsequently, associations between the remaining variables and the occurrence of DD were estimated using a generalized estimating equations model in PROC GENMOD (SAS Institute, 2004), which was corrected for clustering at the herd level. The selection of this population-averaged model instead of a random effect model was based on our interest in an effect across all herds instead of an interest in the individual herd.

To assess the goodness-of-fit of the logistic regression model, the Hosmer Lemeshow statistic was calculated in the LOGISTIC PROCEDURE in SAS (2004). Finally, the population-attributable fraction (PAF) from the predictor variables IDHE, HYP, and IP was calculated according to Bruzzi et al. (1985). The PAF is the fraction of the total disease prevalence in the population that would not have occurred if the risk factor of interest was absent. For the other predictor variables in the model, the PAF was not calculated because of the "fixed" 


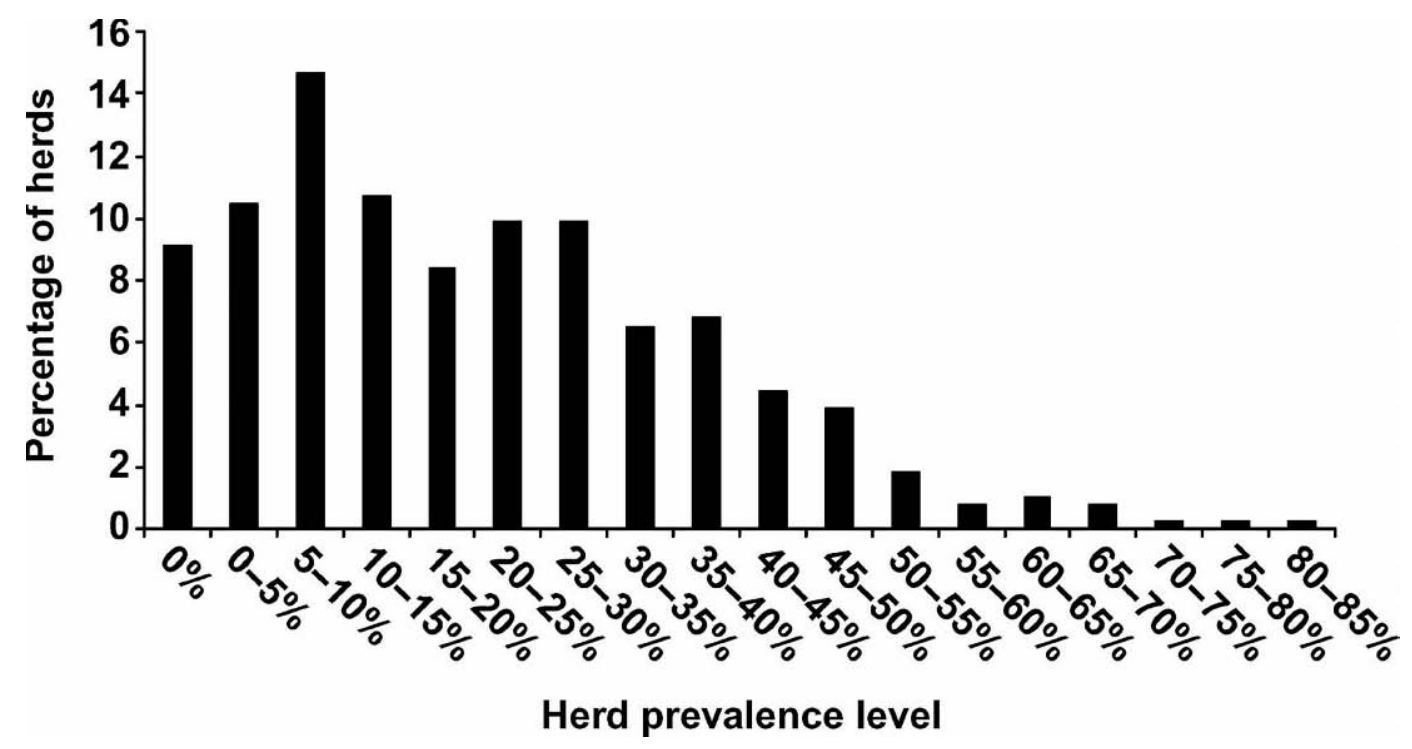

Figure 1. Herd level prevalence of digital dermatitis in 383 herds (22,454 dairy cows) in The Netherlands.

nature of these variables. Formula 1 shows the formula for the calculation of the PAF adjusted for the other variables in the model:

$$
\mathrm{PAF}=1-\sum_{j} \frac{\rho_{j}}{O R_{j}}
$$

$\rho_{j}=\frac{x_{j}}{x}$ (proportion of all cases that are in stratum $\mathbf{j}$ ).

\section{RESULTS}

\section{Descriptive Results}

The average size of the herds in this study was 58.6 $(\mathrm{SE}=1.1)$. The cows were mainly housed in free stalls on slatted floors (92.0\%). In this cross-sectional study, $21.2 \%$ ( $\mathrm{SE}=0.3$ ) of the cows were diagnosed with DD lesions. The herd level prevalence varied from $0.0 \%$ (35 herds $=9.1 \%)$ to $83.0 \%(1$ herd $=0.3 \%)$. A within-herd prevalence between 5 and $10 \%$ was most common (approximately $15 \%$ of the herds; Figure 1).

The prevalence of DD did not vary much between both hind feet: $34.6 \%$ of the affected cows had lesions only on the right hind foot, $35.3 \%$ had lesions on the left foot, and $30.1 \%$ of all affected cows had lesions on both hind feet.

\section{Risk Factors}

In the final multivariable generalized estimating equations model, 9 (interacting) variables were signifi- cantly associated with DD $(P<0.05$; Table 2$)$. Confounding was not present. The herd random effect, calculated in MLWIN 2.01 (2004), was significant, and its variance was estimated as $1.094(\mathrm{SE}=0.095)$. A cluster effect from the hoof trimmers was not significant (variance $=$ $0.115 ; \mathrm{SE}=0.065$ ). The within-herd correlation based on the generalized estimating equations model was estimated as 0.11 . The outcome of the Hosmer and Lemeshow statistic was not significant $\left(\chi^{2}=13.6 ; \mathrm{df}=8 ; P=\right.$ $0.0935)$, implying that the logistic model fitted adequately.

Cow Factors. Purebred [odds ratio $(\mathbf{O R})=1.7$ ] and crossbred Holstein-Friesian cows ( $\mathrm{OR}=1.7$ to 1.8 ) were at higher risk for DD than MRIJ cows, a dual purpose breed. The risk of having DD generally decreased with increasing parity (independent of interactions; Table 2). Dry cows in their first lactation were at lower risk for DD $(\mathrm{OR}=0.8)$ than were cows in late lactation $(>60$ DIM; reference group). The peak of lactation (30 to 60 DIM) was positively associated with $\mathrm{DD}(\mathrm{OR}=1.4)$ within the group of third-parity cows.

A positive association was found between other infectious claw disorders and DD. The presence of IDHE, HYP, and IP were all positively associated with the presence of DD. An interaction between HYP and herd size was present. The risk of having DD within the group of IDHE-affected animals slightly decreased with longer access to pasture.

If IDHE had not been present among the study population, 32.3\% of the DD cases would not have been present. Approximately $9 \%$ of the DD cases would not have been present if HYP were not present. Although 
Table 2. Odds ratios (OR; including 95\% confidence interval), frequencies, and digital dermatitis (DD) prevalence for the variables associated with DD among 22,454 cows on 383 farms in The Netherlands. The OR of the interactions is presented as stratum-specific OR

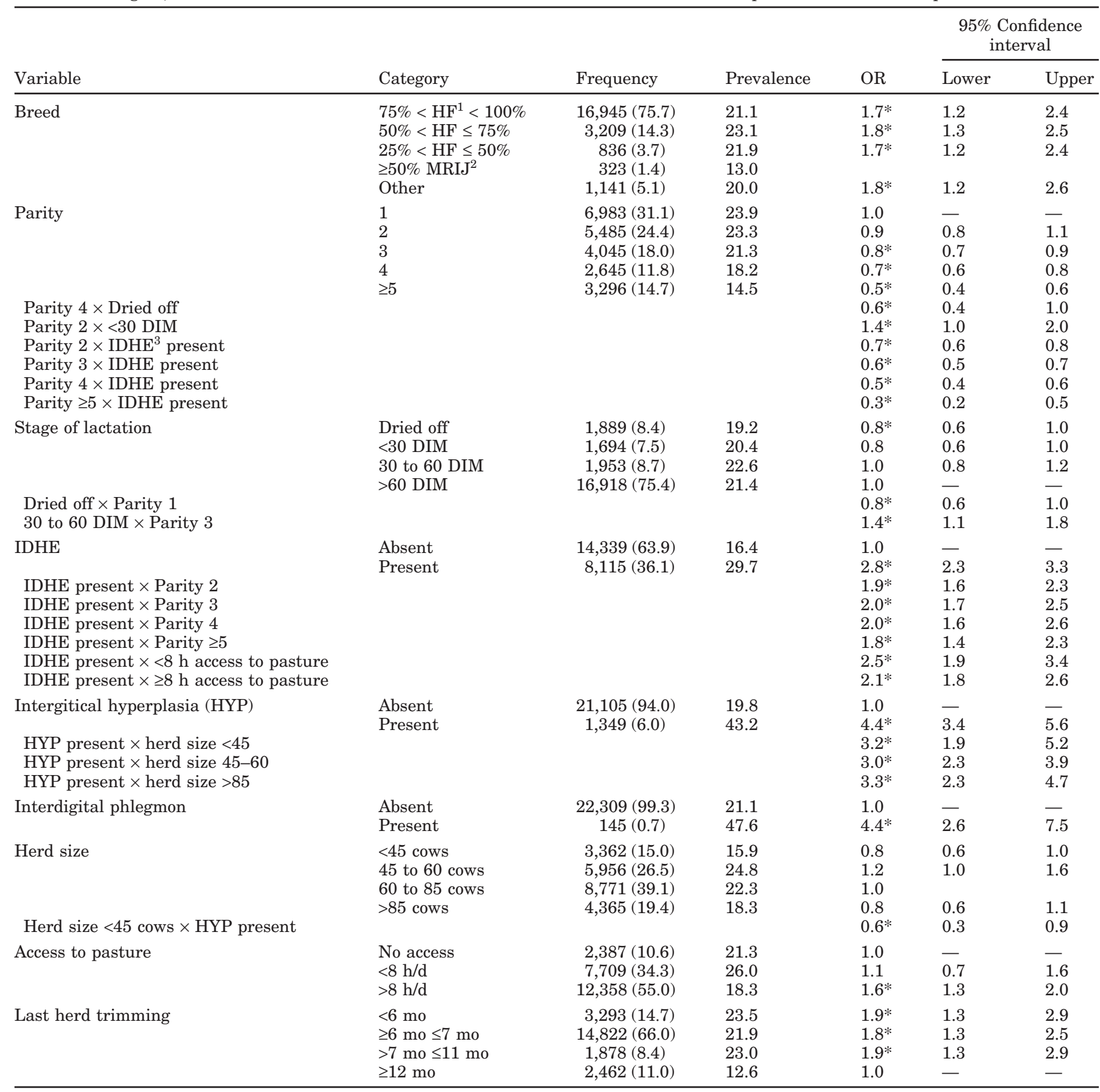

\footnotetext{
${ }^{1} \mathrm{HF}=$ Holstein-Friesian.

${ }^{2}$ MRIJ = Meuse Rhine IJssel.

${ }^{3} \mathrm{IDHE}=$ Interdigital dermatitis/heel horn erosion.

$* P<0.05$.
}

IP appeared to be strongly associated with $\mathrm{DD}(\mathrm{OR}=$ 4.4), its PAF is low (1.1\%) because of the low number of cases.
Management Factors. Trimming policy had an effect on the presence of DD. It appeared that cows trimmed (during regular trimming of all dairy cows in 
a herd) $>12$ mo before the study were at lower risk than were cows trimmed at shorter intervals. Furthermore, animals that had $>8 \mathrm{~h}$ access to pasture were at higher risk for $\mathrm{DD}(\mathrm{OR}=1.6)$ compared with no access to pasture. Finally, cows in small size herds $(<45$ cows) that were affected with HYP were at lower risk $(\mathrm{OR}=$ $0.6)$ of having DD than were cows in medium- or largesized herds (60 to 85 cows per herd).

Other variables with regard to management and housing, such as floor type, free-stall bedding, use of manure scraper, use of footbath, herd size, purchase of heifers, and action taken when observing lameness, were not significantly associated with DD.

\section{DISCUSSION}

The objective of this study was to determine the cow and herd prevalence of DD in The Netherlands and to identify and quantify the effect of associated risk factors. In this cross-sectional study, $21.2 \%$ of the study population was diagnosed with DD lesions. About 9\% of the herds was unaffected, and a DD prevalence between 5 and $10 \%$ of the cows in a herd was most common. The main risk factors associated with DD were breed; parity; stage of lactation; presence of IDHE, HYP, and IP; herd size; herd trimming interval; and access to pasture.

The prevalence of DD in this study is lower than the prevalence in the study performed by Somers et al. (2005a) (27.3\% in the pasture period and $28.5 \%$ in the housing period). The differences in results might be due to dissimilarity in the objective of the study, a slightly different study population, a different sampling period, and a distinct different background of the observers (hoof trimmers vs. individual investigator). In the study of Frankena et al. (1991), 8.1\% (pasture period) and $13.8 \%$ (housing period) of the population were affected with DD. Smits et al. (1992) found a prevalence of $17.6 \%$ in zero-grazing cows. Although some differences in the diagnosis might have occurred, it is not likely that the increase in DD prevalence in the last decade in The Netherlands is solely due to improved diagnosis. The probability of infection might have truly increased because of prolonged housing periods.

\section{Study Population and Data Collection}

The average size of the herds in this study was 58.6 ( $\mathrm{SE}=1.1$, which was comparable with the average of Dutch dairy farm $(\bar{\chi}=56.3$; Dutch Central Office for Statistics, 2003). Ninety-two percent of the cows in this study were housed in free stalls on slatted floors. The remaining cows were housed on partly solid concrete floors and other housing systems such as straw yards, which is comparable with the Dutch population of dairy herds (Braam and Swierstra, 1997).

\section{Breed}

The Holstein-Friesian breed was more susceptible to DD than the MRIJ breed, which agreed with the study of Frankena et al. (1991). It is generally accepted that the MRIJ breed suffers less from claw and leg disorders than the Holstein-Friesian breed (Grommers, 1967; Peterse, 1980).

\section{Parity}

The likelihood for DD generally decreased with increasing parity. This is in agreement with the results of Frankena et al. (1991), Smits et al. (1992), Read and Walker (1998b), Rodrigues-Lainz et al. (1999), and Somers et al. (2003, 2005a). The high OR in heifers could be explained by the metabolic and environmental changes before and after calving and the stress associated with this event (Frankena et al., 1991; RodriguesLainz et al., 1999; Somers et al., 2005a). The decreasing risk for DD with increasing parity might be due to increased local immunity with age or culling of older affected cows (Frankena et al., 1991; Rodrigues-Lainz et al., 1999; Somers et al., 2005a). It is notable that second-parity cows in early lactation are at higher risk for DD than are heifers in early lactation. The reason for this result is not clear but might be related to different feeding or management strategies.

\section{Stage of Lactation}

Cows were at lower risk for DD when dried off (in first parity). This corresponded with findings of Frankena et al. (1991), Smits et al. (1992), Argaez-Rodriguez et al. (1997), Murray et al. (2002), and Somers et al. (2005a). They all concluded that cows in the dry period were less affected with DD than were lactating cows. Dry cows are generally fed another ration with a higher proportion of roughage, resulting in more solid feces. Accordingly, these cows are less exposed to wet and unhygienic conditions (Somers et al., 2005a). Another explanation might be an increase in $\mathrm{pH}$ of the feces because of the change in ration (less concentrates), causing a deteriorated environment for the survival of the infectious agents of DD.

Argaez-Rodriguez et al. (1997) found in their research that the highest risk for DD was in the first month of lactation. The results of our study, however, showed early lactation (0 to 30 DIM) as a nonsignificant factor (in comparison to $>60$ DIM). However, peak lactation (30 to $60 \mathrm{DIM}$ ) interacting with third parity was posi- 
tively associated with $\mathrm{DD}(\mathrm{OR}=1.4)$. This is in agreement with the research of Frankena et al. (1991) who also concluded that cows at peak production (30 to 70 DIM) had a high risk for DD, which the researchers explained to be a result of greater susceptibility. The difference with the findings of Argaez-Rodriguez et al. (1997) might be related to dissimilar management or climatic circumstances.

\section{Infectious Claw Disorders}

The presence of other infectious claw disorders, such as IDHE and IP, increased the risk for DD. As in this study, the results of the epidemiological study of Manske et al. (2002a) showed that IDHE was strongly correlated with DD, suggesting that IDHE and DD might be both parts of the same process and share common causative mechanisms. These infections could also be facilitated by certain common (unhygienic) circumstances (Bargai, 1998). The correlation between HYP and DD offers support for the association between a chronic irritation of the skin and the development of HYP (Manske et al., 2002a). In addition, there are pathological indications that the infectious agent of IDHE also plays a role in the pathogenesis of DD (e.g., Koniarova et al., 1993; Blowey et al., 1994; Walker et al., 1995).

The results suggest that longer access to pasture slightly decreases the risk for DD in IDHE-affected cows. Somers et al. (2005b) also mentioned the preventive effect of grazing on the occurrence of IDHE, probably caused by reduced exposure to the unfavorable housing environment or spontaneous healing of small lesions on pasture, which might positively influence DD prevalence.

Based on the PAF, it was estimated that if IDHE, HYP, and IP were not present among the study population, respectively, 32,9 , and $1 \%$ of the DD cases would not have been present. Therefore, an effective intervention strategy against DD should not solely emphasize the prevention, treatment, or control of DD itself, but should also consider an integrated approach to the control of all infectious claw diseases.

Sole hemorrhages, chronic laminitis, White Line Disease, and sole ulcer were not associated with the occurrence of $\mathrm{DD}$, which is explicable by the fact that these disorders are not infectious.

\section{Herd Size}

Cows in smaller herds ( $<45$ cows) that were affected with HYP were at lower risk $(\mathrm{OR}=0.6)$ for DD than were medium- and large-sized herds (60 to 85 cows per herd). This result might be explained by a presumably lower exposure level to pathogens in smaller herds (Frankena et al., 1991).

\section{Access to Pasture}

This research showed that $>8 \mathrm{~h}$ access to pasture is positively associated with DD. In contrast, Frankena et al. (1991) and Somers et al. (2005a) showed a positive association between limited access to pasture and the occurrence of DD compared with free access to pasture. An explanation for the result in this study might be that the herdsman might decide to provide the cows with longer access to pasture when cows are experiencing claw disorders.

\section{Claw Care Management}

In this study, a long trimming interval ( $\geq 12 \mathrm{mo}$ ) was negatively associated with DD. This result is in contrast to results from Rodrigues-Lainz et al. (1999) and Somers et al. (2005a), who concluded that a long interval between herd trimmings was positively associated with DD. There could be 2 reasons for the results in this study. First, hoof trimming might be used as a curative measure when the herd is experiencing an infection or when the herd has a history of claw infections. Second, the hoof trimmer might be a source of infection because of unwashed equipment between cows and farms (Wells et al., 1999). Therefore, the exposure increases with a shorter trimming interval. In the study of Wells et al. (1999), 48\% of the cases of DD could have been prevented when the hoof trimmer did not also operate on other farms.

This study did not show evidence of an effect of housing system and free-stall bedding on the presence of DD, as mentioned by Peterse (1987), Frankena et al. (1991), Laven (1999), and Somers et al. (2003). Although studies in North and South America (RodriguesLainz et al., 1996, 1999; Wells et al., 1999) showed the purchase of heifers as a strong predisposing factor for $\mathrm{DD}$, this variable appeared to be nonsignificant in this study. Also, no effect of manure scraper was found in this study, which is in contradiction to the results of Somers et al. (2003) and Laven (1999). Furthermore, the use of a footbath did not have any association with DD. This disagrees with research from Rodrigues-Lainz et al. $(1996,1999)$ and Somers et al. (2005a).

Finally, it has to be kept in mind that a cross-sectional study is measuring the association between exposure and the diseases that are measured simultaneously. No conclusions of causality can be drawn, except for those factors that do no not change over time, such as breed. 


\section{CONCLUSIONS}

The results of this study showed factors associated with the presence of DD in The Netherlands. As found in other studies, cow factors, such as parity, stage of lactation, and breed, appeared to be associated with DD. Furthermore, management factors, such as access to pasture and herd trimming policy, were related to DD. This study also provided some more epidemiological insights into the relationship between DD and other infectious claw diseases, such as IDHE, HYP, and IP. Finally, interactions between the associated risk factors were identified. The reevaluation of the interacting risk factors associated with DD in The Netherlands might assist in the prevention of this disorder in The Netherlands and in other countries.

\section{ACKNOWLEDGMENTS}

The authors thank Bart van den Borne (Animal Health Service) for his assistance with data entry and analysis and Gerdien van Schaik (Animal Health Service) for her helpful comments on this manuscript. The cooperation of all dairy farmers and hoof trimmers in this study was greatly appreciated. Furthermore, the authors acknowledge the Dutch Herd Book Organization for their data. This study was funded by the Dairy Commodity Board (Rijswijk, The Netherlands).

\section{REFERENCES}

Argaez-Rodriguez, F., D. W. Hird, J. Hernandez de Anda, D. H. Read, and A. Rodriguez-Lainz. 1997. Papillomatous digital dermatitis on a commercial dairy farm in Mexicali. Mexico: Incidence and effect on reproduction and milk production. Prev. Vet. Med. 32:275-286.

Bargai, U. 1998. Digital dermatitis, interdigital dermatitis and heel horn erosion-Are they separate diseases? Page 265 in Proc. 10th Symp. Lameness in Ruminants, Lucerne, Switzerland.

Basset, H. F., M. L. Monaghan, P. Lenhan, M. L. Doherty, and M. E. Carter. 1990. Bovine digital dermatitis. Vet. Rec. 126:164-165.

Blowey, R. W., S. H. Done, and W. Cooley. 1994. Observations on the pathogenesis of digital dermatitis in cattle. Vet. Rec. 135:115-117.

Blowey, R. W., and M. W. Sharp. 1988. Digital dermatitis in dairy cattle. Vet. Rec. 122:505-508.

Braam, C. R., and D. Swierstra. 1997. Developments in design of concrete floors in dairy cattle houses: Impact of environmental demands. Pages 11-22 in Proc. Concrete for a Sustainable Agriculture, Stavanger, Norway.

Brizzi, A. 1993. Bovine digital dermatitis. Bovine Pract. 33:33-35.

Bruzzi, P., S. B. Green, D. P. Byar, L. A. Brinton, and C. Schairer. 1985. Estimating the population attributable risk for multiple risk factors using case-control data. Am. J. Epidemiol. 122:904-914.

Cheli, R., and C. Mortellaro. 1974. La dermatite digitale del bovine. Pages 208-213 in Proc. 8th Int. Conf. Diseases of Cattle, Milan, Italy.

Clarkson, M. J., D. Y. Downham, W. B. Faull, J. W. Hughes, F. J. Manson, J. B. Merritt, R. D. Murray, W. B. Russel, J. E. Sutherst, and W. R. Ward. 1996. Incidence and prevalence of lameness in dairy cattle. Vet. Rec. 138:563-567.
Cornelisse, J. L., D. J. Peterse, and E. Touissaint-Raven. 1981. A digital disorder in dairy cattle, digital dermatitis? Neth. J. Vet. Assoc. 106:452-455.

Dawson, J. C. 1999. Treatment of digital dermatitis. Cattle Pract. $7: 355-356$

Demirkan, I., R. D. Murray, and S. D. Carter. 2000. Skin diseases of the bovine digit associated with lameness. Vet. Bull. 70:149-171.

Demirkan, I., R. L. Walker, R. D. Murray, R. W. Blowey, and S. D. Carter. 1999. Serological evidence of spirochaetal infections associated with digital dermatitis in dairy cattle. Vet. J. 157:69-77.

Döpfer, D., A. Koopmans, F. A. Meijer, I. Szakál, Y. H. Schukken, W. Klee, R. B. Bosma, J. L. Cornelisse, A. J. A. M. van Asten, and A. A. H. M. ter Huurne. 1997. Histological and bacteriological, evaluation of digital dermatitis in cattle, with special reference to spirochaetes and Campylobacter faecalis. Vet. Rec. 140:620-623.

Dutch Central Office for Statistics. 2003. Agricultural Census 2003. Statistics Netherlands, ed. Elsevier, Voorburg, The Netherlands.

Enting, H., D. Kooij, A. A. Dijkhuizen, R. B. M. Huirne, and E. N. Noordhuizen-Stassen. 1997. Economic losses due to clinical lameness in dairy cattle. Livest. Prod. Sci. 49:259-267.

Espinasse, J., M. Savey, C. M. Thorley, E. Touissaint Raven, and A. D. Weaver. 1982. Page 48 in Atlas en Couleur des Affections du Pied des Bovines et des Ovins. Editions du Point Vétérinaire, Maison-Alfort, France.

Frankena, K., and E. A. M. Graat. 2001. Multivariate analysis: Logistic regression. Pages 133-173 in Application of Quantitative Methods in Veterinary Epidemiology, 2nd ed. J. P. T. M. Noordhuizen, K. Frankena, M. V. Thrusfield, and E. A. M. Graat, ed. Wageningen Press, Wageningen, The Netherlands.

Frankena, K., E. N. Stassen, J. P. Noordhuizen, J. O. Goelema, J. Schipper, H. Smelt, and H. Romkema. 1991. Prevalence of lameness and risk indicators for digital dermatitis during pasturing and housing of dairy cattle. Pages 107-118 in Proc. Annu. Symp. Soc. Vet. Epid. Prev. Med., London, UK.

Garbarino, E. J., J. A. Hernandez, J. K. Shearer, C. A. Risco, and W. W. Thatcher. 2004. Effects of lameness on ovarian activity in postpartum Holstein cows. J. Dairy Sci. 87:4123-4131.

Grommers, F. J. 1967. Dairy cattle housing and health. Ph.D. Diss., Univ. Utrecht, The Netherlands.

Kimura, Y., M. Takahasi, and N. Matsumoto. 1993. Verrucose dermatitis and digital papillomatosis in dairy cows. J. Vet. Med. Jpn. 46:899-906.

Koniarova, I., A. Orsag, and V. Ledecky. 1993. The role anaerobes in digital dermatitis et interdigitalis in cattle. Vet. Med. (Praha) 38:589-596.

Laven, R. A. 1999. The environment and digital dermatitis. Cattle Pract. 7:349-354.

Manske, T., J. Hultgren, and C. Bergsten. 2002a. Prevalence and interrelationships of hoof lesions and lameness in Swedish dairy cows. Prev. Vet. Med. 54:247-263.

Manske, T., J. Hultgren, and C. Bergsten. 2002b. Topical treatment of digital dermatitis associated with severe heel-horn erosion in a Swedish dairy herd. Prev. Vet. Med. 53:215-231.

McLennan, M. W., and R. A. McKenzie. 1996. Digital dermatitis in a Friesian cow. Aust. Vet. J. 74:314-315.

MLWIN User's Guide to MLWIN. Version 2.0. 2004. Centre for Multilevel Modelling, Institute of Education, London, UK.

Murray, R. D., D. Y. Downham, I. Demirkan, and S. D. Carter. 2002. Some relationships between spirochaete infections and digital dermatitis in four UK dairy herds. Res. Vet. Sci. 73:223-230.

Nutter, W. T., and J. A. Moffit. 1990. Digital dermatitis control. Vet. Rec. 126:200-201.

Peterse, D. J. 1980. Judgment of bovine claws by the occurrence of sole lesions. Ph.D. Diss., Univ. Utrecht, The Netherlands.

Peterse, D. J. 1987. Aetiology of claw disorders in dairy cattle. Pages 3-7 in Proc. Cattle Housing Systems, Lameness and Behaviour, Brussels, Belgium. H. K. Wierenga, and D. J. Peterse, ed. Martinus Nijhoff Publishers, Dordrecht, The Netherlands.

Read, D. H., and R. L. Walker. 1998a. Papillomatous digital dermatitis (footwarts) in California dairy cattle: Clinical and gross pathologic findings. J. Vet. Diagn. Invest. 10:67-76. 
Read, D. H., and R. L. Walker. 1998b. Comparison of papillomatous digital dermatitis and digital dermatitis of cattle by histopathology and immunohistochemistry. Pages 268-269 in Proc. 10th Symp. Lameness in Ruminants, Lucerne, Switzerland.

Rodrigues-Lainz, A., D. W. Hird, T. E. Carpenter, and D. H. Read. 1996. Case-control study of papillomatous digital dermatitis in southern California dairy farms. Prev. Vet. Med. 28:117-131.

Rodrigues-Lainz, A., P. Melendez-Rentamal, D. W. Hird, D. H. Read, and R. L. Walker. 1999. Farm- and host-level risk factors for papillomatous digital dermatitis in Chilean dairy cattle. Prev. Vet. Med. 42:87-97.

SAS Institute. 2004. SAS User's Guide. Statistics, Version 9.1. SAS Inst., Inc., Cary, NC.

Schroeder, C. M., K. W. Parlor, T. L. Marsh, N. Kent Ames, A. K. Goeman, and R. D. Walker. 2003. Characterization of the predominant anaerobic bacterium recovered from digital dermatitis lesions in three Michigan dairy cows. Anaerobe 9:151-155.

Smits, M. C. J., K. Frankena, J. H. M. Metz, and J. P. T. M. Noordhuizen. 1992. Prevalence of digital disorders in zero-grazing dairy cows. Livest. Prod. Sci. 32:231-244.

Socha, M. T., D. J. Tomlinson, C. J. Rapp, and A. B. Johnson. 2002. Lameness: Diagnosis and impact on reproduction. In Report Hoof Health Conference, Columbus, $\mathrm{OH}$.

Sogstad, A. M., T. Fjeldaas, O. Østerås, and K. Plym Forshell. 2005. Prevalence of claw lesions in Norwegian cattle housed in tie stalls and free stalls. Prev. Vet. Med. 70:191-209.

Somers, J. G. C. J., K. Frankena, E. N. Noordhuizen-Stassen, and J. H. M. Metz. 2003. Prevalence of claw disorders in Dutch dairy cows exposed to several floor systems. J. Dairy Sci. 86:2082-2093.
Somers, J. G. C. J., K. Frankena, E. N. Noordhuizen-Stassen, and J. H. M. Metz. 2005a. Risk factors for digital dermatitis in dairy cows kept in cubicle houses in The Netherlands. Prev. Vet. Med. $71: 11-21$.

Somers, J. G. C. J., K. Frankena, E. N. Noordhuizen-Stassen, and J. H. M. Metz. 2005b. Risk factors for interdigital dermatitis and heel erosion in dairy cows kept in cubicle houses in the Netherlands. Prev. Vet. Med. 71:23-34.

Trott, D. J., M. R. Moeller, R. L. Zuerner, J. P. Goff, W. R. Waters, D. P. Alt, R. L. Walker, and M. J. Wannemuehler. 2003. Characterization of Treponema phagedenis-like spirochetes isolated from papillomatous digital dermatitis lesions in dairy cattle. J. Clin. Microbiol. 41:2522-2529.

van Amstel, S. R., S. van Vuuren, and C. L. Tutt. 1995. Digital dermatitis: Report of an outbreak. J. S. Afr. Vet. Assoc. 66:177-181.

Vermunt, J. J., and F. L. Hill. 2004. Papillomatous digital dermatitis in a Holstein-Friesian bull. N. Z. Vet. J. 52:99-101.

Walker, R. L., D. H. Read, K. J. Loretz, and R. W. Nordhausen. 1995. Spirochetes isolated from dairy cattle with papillomatous digital dermatitis and interdigital dermatitis. Vet. Microbiol. 47:343355.

Wells, S. J., L. P. Garber, and B. A. Wagner. 1999. Papillomatous digital dermatitis and associated risk factors in US dairy herds. Prev. Vet. Med. 38:11-24.

Zemljic, B. 2004. Influence of footbathing on prevalence of digital dermatitis after introduction of diseased animals into healthy dairy herd. Pages 145-147 in Proc. 13th Symp. Lameness in Ruminants, Maribor, Slovenia. 